\title{
Metodologias Ativas na Educação Bilíngue e Bicultural no curso de Letras Libras da Universidade Federal do Ceará: Percepção dos alunos
}

\author{
Actives Methodologies in Bilingual-Bicultural Education in Libras Literature Course of Federal \\ University of Ceara: Students' perception \\ Metodologías Activas en la educación bicultural bilingüe en el curso de licenciatura en Libras de la \\ Universidad Federal de Ceará: Percepción de los estudiantes
}

Recebido: 22/05/2021 | Revisado: 29/05/2021 | Aceito: 01/06/2021 | Publicado: 16/06/2021

Antonio Daley Marques do Nascimento
ORCID: https://orcid.org/0000-0002-5209-4382
Universidade Federal do Ceará, Brasil
E-mail: daley.porang@gmail.com
Cauê Jucá Ferreira Marques
ORCID: https://orcid.org/0000-0001-5972-3164
Universidade Federal do Ceará, Brasil
E-mail: cacajucaf@ gmail.com
Marilene Calderaro Munguba
ORCID: https://orcid.org/0000-0002-3663-9282
Universidade Federal do Ceará, Brasil
E-mail: marilenemunguba@ @elles.ufc.br

\begin{abstract}
Resumo
O presente estudo adotou como objetivo descrever a percepção de alunos do curso de licenciatura em Letras Libras da Universidade Federal do Ceará quanto ao uso de metodologias ativas na mediação da educação bilíngue e bicultural. Trata-se de um estudo Survey, descritivo qualitativo, realizado no período de 10 a 30 de setembro de 2020 , com 24 alunos. Como critério de inclusão adotou-se a condição de haver vivenciado presencialmente as metodologias ativas na mediação da aprendizagem, no período de 2018.1 a 2019.2, em pelo menos uma das cinco disciplinas definidas. A amostragem de 24 respondentes foi intencional, no universo de 64 alunos que se distribuiu em 6 (25\%) Surdos e 18 (75\%) ouvintes. Aplicou-se um questionário misto digital por meio da plataforma Google Forms, contendo 10 perguntas fechadas e 2 abertas, todas em Língua Portuguesa e em Libras, para cada uma das sete técnicas de Metodologias Ativas. Os resultados apontam para a efetividade das técnicas no processo de ensino e aprendizado de turmas bilíngues, sobretudo na consolidação da autonomia discente e desenvolvimento da criticidade. Sugere-se pesquisas que avaliem, de mesmo modo, a percepção dos discentes quanto ao uso das Metodologias Ativas como estratégias de avaliação da aprendizagem.
\end{abstract}

Palavras-chave: Metodologias ativas; Educação bilíngue e bicultural; Formação do educador; Ensino superior.

\begin{abstract}
The present study aims to describe the perception of students of the Libras Literature course at the Federal University of Ceará regarding the use of active methodologies in the mediation of Bilingual-Bicultural education. This is a qualitative, descriptive Survey research, carried out from September 10th to 30th, 2020, with 24 students. As an inclusion criterion, it was adopted the condition of having experienced in person the actives methodologies in the mediation of learning, in the period from 2018.1 to 2019.2, in at least one of the five defined disciplines. The sample of 24 respondents was intentional, in the universe of 64 students that was distributed in 6 (25\%) Deaf and 18 (75\%) Hearing. A mixed digital questionnaire was applied through the Google Forms platform, containing 10 closed and 2 open questions, all in Portuguese and in Libras, for each of the seven Active Methodology techniques. The results point to the effectiveness of the techniques in the teaching and learning process of bilingual classes, especially in the consolidation of student autonomy and the development of criticality. A research is suggested to evaluate, in the same way, the students' perception regarding the use of Active Methodologies as strategies for learning assessment.
\end{abstract}

Keywords: Active methodologies; Bilingual-bicultural education; Teacher training; Higher education.

\section{Resumen}

La presente investigación tiene por objetivo describir la percepción de los alumnos del curso de licenciatura en lengua brasileña de señales (Libras) de la Universidad Federal de Ceará acerca del uso de Metodologías Activas en la mediación 
de la educación bicultural bilingüe. La investigación trabaja con un estudio Survey, descriptivo cualitativo, realizado el día 10 hasta 30 de septiembre de 2020, con 24 alumnos. El criterio de inclusión para formar parte de la investigación fue tener experiencias presenciales con las Metodologías Activas en la mediación del aprendizaje, en el período de 2018.1 hasta 2019.2, en por lo menos una de las cinco asignaturas del curso. La cantidad de muestreo, 24 participantes, fue intencional, en un grupo de 64 alumnos que se distribuyeron en 6 (25\%) sordos y 18 (75\%) oyentes. Se aplicó un cuestionario mixto digital por medio de la plataforma Google Forms, conteniendo 10 preguntas cerradas y 2 abiertas, todas estaban en Lengua Portuguesa y en Libras, todas utilizaban las siete técnicas de Metodologías Activas. Los resultados apuntaran para la efectividad de las técnicas en el proceso de enseñanza y aprendizaje de grupos bilingües, sobretodo en la consolidación de la autonomía discente y el desarrollo de la criticidad. Se sugieren investigaciones que evalúen, del mismo modo, la percepción de los discentes sobre el uso de las Metodologías Activas como estrategias de evaluación del aprendizaje.

Palabras clave: Metodologías activas; Educación bilingüe bicultural; Formación del educador; Enseñanza superior.

\section{Introdução}

O debate sobre as metodologias e estratégias de ensino e aprendizagem tem ocorrido de forma significativa desde sempre. Morán (2015, p.18) ressalta que "Teóricos como Dewey (1950), Freire (2009), Rogers (1973), Novack (1999), entre outros, enfatizam, há muito tempo, a importância de superar a educação bancária, tradicional e focar a aprendizagem no aluno, envolvendo-o, motivando-o e dialogando com ele".

O desafio é imenso para o educador o educando, porque ambos precisam refletir sobre suas posturas no âmbito do processo de ensino e aprendizagem. O educador deixa o centro do processo para que o aluno se torne o principal protagonista de sua aprendizagem. Gonçalves (2020, p.16) afirma que o educador “[...] contribui no processo de aprendizagem, na medida em que atua como mediador do processo de ensino e aprendizagem, [...], propondo atividades que tenham a finalidade de envolver o educando, tornando-o partícipe do processo". Dantas (2018) reforça a ideia de que paradigmas da educação vêm sendo quebrados no tocante à função restrita à reprodução do conhecimento, e se voltando para a importância do educador na mediação da construção do saber.

Ressaltamos, ainda, a relevância do processo de ensinagem proposto por Anatasiou em 1998, que vem sendo aprimorado desde então. Trata-se de "uma situação de ensino da qual necessariamente decorra a aprendizagem, sendo a parceria entre professor e alunos a condição fundamental para o enfrentamento do conhecimento, necessário à formação do aluno durante o cursar da graduação" (Anastasiou \& Alves, 2015, p. 20). Nessa perspectiva, a adoção de estratégias diversificadas de mediação, é determinante.

Para tanto, Morán (2015, p.18) especifica componentes determinantes para a otimização da aprendizagem, como

[...] a criação de desafios, atividades, jogos que realmente trazem as competências necessárias para cada etapa, que solicitam informações pertinentes, que oferecem recompensas estimulantes, que combinam percursos pessoais com participação significativa em grupos, que se inserem em plataformas adaptativas, que reconhecem cada aluno e ao mesmo tempo aprendem com a interação, tudo isso utilizando as tecnologias adequadas.

Ao refletir sobre esses componentes, é possível identificar a demanda de promoção do envolvimento e participação do educando, de forma ativa e proativa, que se ancora na proposta de utilização de metodologias ativas (MA) na mediação da aprendizagem. Souza (2015) aponta que as MA, a partir do final do século XIX, já eram apontadas como forma de favorecer o protagonismo do educando. Mattar (2017) enfatiza a relevância dessa proposta em que o educando passa a ser o centro do processo e o educador exerce a função mediadora de propor desafios, orienta atividades para que o planejamento seja cumprido da forma desejada.

Morán (2015, p.18) enfatiza ainda que "as metodologias ativas são pontos de partida para avançar para processos mais avançados de reflexão, de integração cognitiva, de generalização, de reelaboração de novas práticas”. Beck (2018) ressalta que esse processo visa o desenvolvimento da capacidade de aprender competências diferenciadas, no educando. 
Para tanto, o educador precisa revisitar o seu fazer pedagógico. Freire (2002, p.100), ao se referir ao sonho viável enfatiza que "[...] exige de mim pensar diariamente a minha prática; exige de mim a descoberta, a descoberta constante dos limites da minha própria prática, que significa perceber e demarcar a existência do que eu chamo espaços livres a serem preenchidos".

Como o contexto deste estudo se configura no curso de Licenciatura em Letras Libras da Universidade Federal do Ceará, o foco também se volta para a formação de educadores. Utiliza-se esse termo ancorados na diferenciação entre os termos "professor" e "educador", proposta por Freire (2002) apontando que o professor se caracteriza pela competência técnica para a transmissão de conteúdo preestabelecido, sem considerar, muitas vezes, o contexto social e as especificidades de cada aluno. Por outro lado, o educador, além de ministrar aulas, busca se contextualizar ao seu entorno, o que gera uma interação, não somente na sala de aula, mas também na comunidade escolar/educacional, tornando todos atores do processo de aprendizagem, e, consequentemente, provocando evolução nesse processo.

Assim, a preocupação na condução das disciplinas mediadas por uma professora do curso, uma das autoras deste texto, na Unidade de Fundamentos da Educação de Surdos, além da otimização da construção do conhecimento específico a cada uma delas, propiciar aos educandos a oportunidade de vivenciar as metodologias ativas, para que desenvolvam a competência para avaliar o seu futuro uso na sua práxis pedagógica, tanto de surdos como de ouvintes.

Esse fazer pedagógico se faz no âmbito da Educação Bilíngue e Bicultural. Isso porque "o sujeito surdo é um sujeito entre línguas; línguas que coexistem, mas que são postas historicamente em lugares distintos (uma no lugar de língua nacional e outra, de língua de constituição dos sujeitos surdos)” (Baalbaki, 2017, p.340). Então, no curso, até o quarto semestre, a mediação por profissionais tradutores e intérpretes de Libras (TILS) é garantida pela universidade, para que os educandos com reduzido nível de fluência ou desconhecimento da Libras, tenham a acessibilidade ao currículo garantida.

Essa postura tem base na perspectiva de Bortoni-Ricardo \& Dettoni (2009), ao afirmarem que ignorar as diversidades linguísticas e culturais é uma forma de contribuir para que as diferenças sociais se aprofundem e se prolonguem.

Especificamente no tocante ao educando Surdo, Pereira (2011, p. 5), reitera que "[...] o conhecimento de mundo e de língua elaborado pela Língua Brasileira de Sinais permitirá que os alunos surdos vivenciem práticas sociais que envolvam a escrita e, deste modo, constituam o conhecimento da Língua Portuguesa".

Nesse contexto, a adoção de metodologias que favoreçam a efetivação desse direito linguístico, a Pedagogia Visual se mostra determinante, já que o educando Surdo estrutura a sua visão de mundo e constrói a sua identidade e conhecimentos por meio da percepção visual diferenciada. Essa metodologia favorece a ambos educandos - surdos e ouvintes -, privilegiando as experiências visuais embasadas na visualidade surda.

As técnicas, recursos e perspectivas utilizados na pedagogia visual, estão relacionados com o uso da "visão", em vez da "audição", sendo que a imagem na "apreensão do estímulo visual" e perspectiva emergem de acordo com forças bidimensionais e tridimensionais. Esses processos exigem uma nova forma de pensar o nível perceptivo e o processamento visual daquilo que rodeia o sujeito Surdo e qual seu olhar sobre o mundo no processo de ensinar e aprender (Campello, 2008, p. 209).

O presente estudo tem como objetivo descrever a percepção de alunos do curso de licenciatura em Letras Libras da Universidade Federal do Ceará quanto ao uso de metodologias ativas na mediação da Educação Bilíngue e Bicultural.

\section{Metodologia}

O estudo se configura como do tipo Survey que, Gil (2019) afirma se propor a descrever a distribuição de características ou fenômenos que ocorrem em grupos da população. 
O presente estudo se caracteriza, ainda, como descritivo qualitativo que, Lakatos \& Marconi (2017) e Minayo, Deslandes \& Gomes (2015) concordam que se volta para a descrição dos componentes do fenômeno, mediante análise qualitativa das informações.

A investigação foi realizada no período de 10 a 30 de setembro de 2020, com 24 alunos do curso Letras Libras da Universidade Federal do Ceará. Como critério de inclusão adotou-se a condição de haver vivenciado, de forma presencial, metodologias ativas na mediação da aprendizagem, no período de 2018.1 a 2019.2, em pelo menos uma das disciplinas: Teoria da Educação de Surdos, Educação Bilíngue e Bicultural, Teorias da Aprendizagem e Educação de Surdos, Ensino e Aprendizagem de Libras por Meio de Novas Tecnologias, Política e Gestão da Educação Básica.

Definiu-se amostragem intencional, no universo de 64 alunos do curso, tendo 24 respondentes, se constituindo a amostra considerada, que se distribuiu em 6 (25\%) Surdos e 18 (75\%) ouvintes. Lakatos e Marconi (2017) afirmam que a taxa média de devolutiva de questionários é de $25 \%$. Nesse caso, os respondentes configuram 37,5\% do alunado, tornando a amostra satisfatória.

\section{Técnicas de coleta de informações}

Como técnica de coleta de informações, um questionário misto foi elaborado, no Google Forms, especificamente para esta investigação. Para Severino (2016), esse tipo de questionário se configura como um rol de perguntas diversificadas, com previsão de respostas abertas e respostas fechadas.

O referido questionário contém 10 perguntas fechadas e duas abertas para cada uma das técnicas de Metodologias Ativas: exposição dialogada com leitura e discussão de imagens, grupos de integração horizontal-vertical, grupo de verbalização e de observação (GV/GO), júri simulado, mapa mental, workshop e projeto, painel integrado. Adotou-se como base os conceitos propostos por Anastasiou \& Alves (2015), Bordenave \& Pereira (2014) (Quadro 1).

Quadro 1 - Estratégias de Metodologias Ativas adotadas e sua dinâmica de aplicação.

\begin{tabular}{|c|c|}
\hline $\begin{array}{l}\text { Exposição dialogada } \\
\text { (com leitura e discussão de } \\
\text { imagens) }\end{array}$ & $\begin{array}{l}\text { Exposição do conteúdo de forma contextualizada ao conhecimento prévio dos alunos, com a } \\
\text { sua participação ativa. Essa técnica adaptada à Educação Bilíngue adotou a pedagogia visual } \\
\text { utilizando a leitura e discussão de imagens, com vistas a oportunizar análise crítica para a } \\
\text { construção do conhecimento. }\end{array}$ \\
\hline $\begin{array}{c}\text { Grupos de integração } \\
\text { vertical/horizontal }\end{array}$ & $\begin{array}{l}\text { Organiza-se a turma em pequenos grupos, conforme os temas a serem abordados, ficando cada } \\
\text { subgrupo com um conteúdo. Ocorre em duas etapas - cada grupo trabalha o seu conteúdo e } \\
\text { posteriormente os alunos formam grupos heterogêneos com o objetivo de socializar as } \\
\text { discussões anteriores. }\end{array}$ \\
\hline $\begin{array}{c}\text { Grupo de verbalização e de } \\
\text { observação-GV/Go }\end{array}$ & $\begin{array}{l}\text { A turma é organizada em dois grupos com funções alternadas durante a análise de temas. Essas } \\
\text { funções se configuram em verbalização (GV) observação (GO). Os alunos são dispostos em } \\
\text { dois círculos concêntricos. }\end{array}$ \\
\hline Júri simulado & $\begin{array}{l}\text { Simulação de um júri sobre tema polêmico em que os alunos desempenham papéis como: } \\
\text { promotoria, defesa, conselho de sentença, escrivão e juiz. } \\
\text { Visa promover, além da análise crítica sobre um tema, o desenvolvimento da habilidade de } \\
\text { argumentação nos alunos. }\end{array}$ \\
\hline
\end{tabular}




\begin{tabular}{|c|c|}
\hline Mapa mental & $\begin{array}{r}\text { Organização das principais ideias de um texto por meio da construção de um diagrama, } \\
\text { considerando a hierarquia dessas ideias, podendo contemplar a escrita e imagens para } \\
\text { promover a compreensão visual do conteúdo. }\end{array}$ \\
\hline Workshop e projeto & $\begin{array}{r}\text { Também denominado “oficina" se volta para a mediação da aprendizagem por meio da } \\
\text { vivência e resolução de problemas, de forma colaborativa. Associou-se à elaboração de } \\
\text { projeto, construindo juntos. }\end{array}$ \\
\hline Painel integrado & $\begin{array}{r}\text { Se configura como um tipo de debate sobre tema polêmico em que os alunos exercem funções } \\
\text { específicas como: painelistas, debatedores e arguidores. }\end{array}$ \\
\hline
\end{tabular}

Fonte: Adaptado de Anastasiou \& Alves (2015), Bordenave \& Pereira (2014).

Aplicou-se o instrumento de coleta de informações por meio do sistema Google Forms disponibilizado virtualmente mediante os e-mails dos participantes alvos da pesquisa, fornecidos aos pesquisadores pela coordenação do curso. Considerando as especificidades culturais e linguísticas do curso e o perfil bilíngue dos respondentes, o questionário foi elaborado em Língua Portuguesa escrita e traduzido para Libras.

\section{Método de análise das informações}

As informações foram analisadas mediante o método análise de conteúdo do tipo análise temática, nas perspectivas de Bardin (2016) e Minayo, Deslandes \& Gomes (2015), referentes ao que se trata de descobrir os núcleos de sentido, ou núcleos temáticos, que compõem uma comunicação, cuja presença ou frequência signifiquem alguma coisa para o objetivo analítico visado. Foram executadas as três fases preconizadas: leitura flutuante, escolha dos documentos e a formulação de hipóteses e objetivos é feito o tratamento dos resultados obtidos e interpretação.

Sendo os autores deste estudo educadora (e, portanto, mediadora das técnicas) e estudantes do curso de Letras Libras, que vivenciaram as metodologias ativas, os resultados foram analisados e discutidos por meio da literatura especializada e, além disso, das impressões e inferências dos autores enquanto partícipes do processo, o que Lakatos \& Marconi (2017) definem como observação participante.

Núcleos temáticos encontrados durante o processo de análise: Relação com trabalhos em grupo, Desenvolvimento da Autonomia, Mediação da Aprendizagem na Formação Profissional, Visão Crítica, Relação professor/aluno e Intérprete Educacional.

\section{Preceitos éticos}

Foi observado o que preconiza a Resolução N510, de 07 de abril de 2016, do Conselho Nacional de Saúde (Brasil, 2016), que dispõe sobre as normas aplicáveis as pesquisas em Ciências Humanas e Sociais.

Art. $1^{\circ}$ Esta Resolução dispõe sobre as normas aplicáveis a pesquisas em Ciências Humanas e Sociais cujos procedimentos metodológicos envolvam a utilização de dados diretamente obtidos com os participantes ou de informações identificáveis ou que possam acarretar riscos maiores do que os existentes na vida cotidiana, na forma definida nesta Resolução. [...]

Durante o percurso foram preservados: Livre participação do estudo, oficializada mediante a assinatura do Termo de Consentimento Livre Esclarecido Pessoal; confidencialidade e privacidade; respeito aos valores culturais, sociais, morais, religiosos, hábitos e costumes; retorno dos benefícios obtidos por meio da pesquisa aos envolvidos na mesma. 


\section{Resultados e Discussão}

Durante o processo de análise das informações, foram identificados os núcleos temáticos que serão abordados e analisados a seguir.

\section{Estabelecimento de relações nos trabalhos em grupo}

Os trabalhos em grupo são parte das bases da construção de uma Metodologia Ativa realmente engajada (Diesel, Baldez \& Martins, 2017). E, para que isso seja pleno, é necessário que esses momentos sejam o mais produtivo possível. Mertizig et al. (2020) ressaltam que esse tipo de estratégia proporciona, além do processo de aprendizagem embasado na autonomia e no desenvolvimento de habilidades determinantes na formação profissional, o ingresso e a permanência no mundo do trabalho.

A melhoria na relação em grupos é identificada e se mostra ser bastante significativa, já que na pesquisa sempre a metade ou a maioria dos respondentes sente essa influência, indicando que a aplicação dessas metodologias está fundamentada nessas bases e conseguindo atingir essa interação.

Freire (2014) enfatiza que, durante o processo de trabalho em grupo, o educador mantém o nível de conteúdo a ser trabalhado pela equipe, e, assim, a interação e engajamento dos integrantes evidencia as forças e fraquezas de cada participante, e a forma que o grupo lida com isso materializa a autonomia, sendo de responsabilidade do grupo, e não mais do educador, o desenvolvimento da atividade proposta.

No caso específico dos mapas mentais, o sentimento desse engajamento em grupo é bem menor, no entanto pode-se inferir que, como essa técnica pode ser usada também para estudos individualizados, esta experiência possa se sobressair e contribuir indiretamente nesse processo de compartilhamento coletivo. A aplicação das técnicas está sujeita à adequação que vai depender dos objetivos pedagógicos e do perfil dos envolvidos. Abreu \& Masetto (1990 apud Borges \& Alencar, 2014) discorrem sobre a possibilidade de mudanças a partir da experiência, criatividade e reflexão que o professor vai tendo no uso das estratégias, nesse caso temos um cruzamento de metodologias que se complementam.

As propostas que valorizam a interação em grupos fornecem grandes avanços dentro do curso e do perfil de profissional que se almeja formar, e, com isso, as trocas culturais são importantes e devem ser incentivadas, pois dentro de uma realidade acadêmica bilíngue e bicultural, as culturas convivem mutuamente e cabe aos envolvidos no curso pensar e usar estratégias que reduzam os atritos e maximizem o multiculturalismo. O comentário de um aluno reflete como isso ocorre e o afeta: “[Acessibilidades] contribuem e facilitam o acesso a informações e conhecimentos, além de promover uma maior interação surdo/ouvinte" (Aluno 10). Com isso se percebe o valor da garantia de acessibilidade e o rompimento de uma impossibilidade de interação entre sujeitos de culturas diferentes. Nesse sentido, Laraia (2001) defende o conceito de relativismo cultural, ou seja, a convivência harmoniosa entre os mais diversos grupos culturais. Especificamente no campo do currículo universitário, Silva (2017), ao apresentar o movimento multiculturalista, destaca as reivindicações de grupos culturais minoritários por visibilidade nas universidades dos países do Norte. Comparativamente, essas lutas assemelham-se ao movimento histórico dos Surdos brasileiros por uma educação que valide suas manifestações culturais.

Em Júri Simulados e em Workshops/Projetos o aprimoramento das relações em grupo é de grande importância, o alunado participante define as MA citadas com mais de 50\% de aceitabilidade como influenciadoras nesse relacionamento coletivo. Isso se dá pela intensa necessidade de negociação entre os colegas na construção de atividade envolvendo essas duas atividades os conhecimentos práticos ou mais próximos da realidade são bastante usados na execução dessas técnicas. Vejamos como um dos alunos pontua: 
de acordo com as minhas experiências o mais difícil para renovar as práticas de ensino é a falta de exemplo prático, muitas vezes ficamos apenas na teoria, parece um mundo idealizado que diverge da realidade. Por isso ter contato direto me ajudou na hora de planejar e colocar em prática o que aprendi. (Aluno 13)

Mesmo que em algumas MA os trabalhos em equipe tenham provocado uma ótima experiência e a garantia de acessibilidade minimize os entraves, alguns participantes reconhecem que nem todos os alunos se interessam.

\section{[...] nem todos participam de forma ativa, uns têm uma facilidade maior para se expressar e acabam participando} mais, porém, é perceptível que pelo menos em algum momento todos da turma acabaram participando das discussões etc. (Aluno 11)

Nesse relato sobre os Grupos de integração Horizontal-Vertical é perceptível que há outras variantes que definem o sucesso desse uso. Pensar em como uma técnica pode ser usada em dado contexto requer ousadia, assim como vemos acima existem alunos que se sentem mais confortáveis e outros, inicialmente, não, provavelmente devido à exposição requerida pela técnica. O mais importante é ver que mesmo o aluno citando essa situação de reduzida interação inicial, reconhece que em algum grau houve participação.

Por fim, é fundamental considerarmos a particularidade bilíngue e bicultural do curso e sua influência nas interações e trabalhos em grupo. Observou-se certo receio e/ou insegurança por parte dos ouvintes não fluentes em Libras em compor equipes com alunos Surdos, como afirma o respondente: “[...]no início do curso nem todos os ouvintes têm fluência na Libras e isso causa uma separação clara entre ouvintes e surdos, tanto em discussões como na organização de trabalhos. Os intérpretes têm um papel de grande relevância em sala aula." (Aluno 20). Marques et. al. (2020), identificando o perfil do alunado do curso de Letras Libras da UFC, afirmam que o curso não tem por objetivo o ensino da língua, mas a formação de professores de Libras, todavia parte significativa dos estudantes $(38,6 \%)$ ingressou na licenciatura sem conhecimentos mínimos de Libras. Nesse sentido, infere-se que essa barreira comunicativa seja uma das principais justificativas para essa insegurança, apesar da presença dos profissionais Tradutores e Intérpretes de Libras (TILS) em todos os momentos. De modo complementar, Gesser (2012) considera esse conflito como pertinente a ouvintes aprendizes de Libras, afinal desconhecem os aspectos linguísticos, culturais e conversacionais da Comunidade Surda.

Cabe investigar, portanto, se nos semestres finais do curso, quando se espera que todos tenham alcançado certo grau de fluência, essa insegurança tenha sido sanada, garantindo a plenitude da inclusão bilíngue/cultural ${ }^{1}$ (Campos, 2018).

\section{Desenvolvimento da autonomia}

A autonomia é de grande importância para nossa existência como seres sociais e cidadãos participativos e isso se acentua quando pensamos na formação de profissionais que serão responsáveis pela formação de outras pessoas. Os alunos da Licenciatura em Letras Libras tiveram oportunidades, com as Metodologias Ativas, de vivenciar formas diferenciadas de aprendizagem que, segundo Berbel (2011), são essenciais para uma experiência mais ampla de possibilidades onde a atuação profissional será beneficiada e a autonomia é exercida.

Na pesquisa em tela, a compreensão de que a autonomia foi estimulada revela-se quando a maioria dos alunos sentiu influência significativa para desenvolver autonomia no cotidiano acadêmico, somando mais da metade nas respostas das diversas

\footnotetext{
1 “[...] aquela em que os surdos são inseridos dentro da escola de ouvintes com colegas ouvintes, mas tem-se naquele espaço a cultura surda com metodologias/currículos adaptados à experiência visual. As aulas são ministradas por professores surdos, professores bilíngues. Também há professores ouvintes que precisam no acompanhamento do ILS [Intérprete de Língua de Sinais] para interpretação dos conteúdos e mediação entre os alunos surdos.” (Campos, 2018, p. 49).
} 
MA e revelando um resultado acima de $90 \%$ para MA tipicamente coletivas como os GV/GO e grupos de integração horizontal/vertical.

Reflexões causadas pelo uso das metodologias podem ser identificadas nas falas de alguns dos participantes: "[...] foram experiências que, certamente, vou reproduzir em minha futura atuação profissional.” (Aluno 01); “[...] eu farei sim algumas das metodologias ativas na minha sala de aula [...]" (Aluno 4) e "[...] foi possível copiar sua estrutura para futuras atividades aplicadas no âmbito da atuação profissional [...]" (Aluno 7). Os relatos mostram uma forte identificação com as metodologias usadas. Essas intenções futuras representam um desenvolvimento autônomo e crítico, pois para que essas atitudes possam surgir o aluno está sob uma visão diferenciada do que é ser um formador de novos sujeitos, como esperado no perfil do egresso definido pelo Projeto Pedagógico Curricular do Curso (Universidade Federal do Ceará, 2012)

A construção de uma pesquisa como essa corrobora com o que Diesel, Baldez \& Martins (2017) sinalizam sobre a postura investigativa do professor e consequentemente dos futuros professores, dialogando com os pressupostos freireanos que concebem a reflexão crítica sobre a prática como exigência do "ensinar" (Freire, 2017a). Oportunizar aos alunos que opinem sobre como foi aplicada e como pode ser aprimorado o uso dessas metodologias os coloca em outro patamar de relevância, visto que além de poderem vivenciar o uso de métodos diferenciados, podem contribuir para a adaptação e o refinamento desses.

$\mathrm{Na}$ condição de partícipes das técnicas, os autores deste trabalho notam, por meio da interação com os demais estudantes em contextos formais e informais do cotidiano universitário, certo espanto com as técnicas em um primeiro momento, sob a justificativa de que, anteriormente, os pares não haviam vivenciados estratégias de mediação que validassem a sua participação e seus conhecimentos prévios, agregando uma nova perspectiva de atuação docente a esses futuros profissionais.

Segundo Thadei $(2018$, s.p.) "a reprodução de práticas há tempos questionadas deve-se não ao desconhecimento da importância da aprendizagem mediada, mas, em parte ao conhecimento superficial sobre a mediação", nos levando a entender que os alunos-pesquisadores-participantes, orientados pela professora mediadora, rompem aqui uma parte desse desconhecimento, visto que houve muita leitura, reflexão e diálogo, resultando, assim, num aprofundamento fundamental para um aprendizado significativo sobre metodologias ativas na mediação em espaços bilíngues e biculturais.

Em pesquisa, Paiva et. al. (2015) percebem a concentração das Metodologias Ativas na área da saúde e o caminhar timidamente para as Ciências Sociais. Com isso, aplicar e construir pesquisas dentro da educação movimenta uma nova narrativa para essas metodologias e para as futuras gerações de educadores e educandos.

\section{O intérprete educacional na mediação}

O Projeto Pedagógico Curricular (PPC) do curso de Letras Libras da UFC destaca a importância da mediação do tradutor e intérprete nas práticas bilíngues e salienta que os profissionais vinculados ao curso constituirão uma divisão vinculada à Secretaria de Acessibilidade - UFC Inclui (Universidade Federal do Ceará, 2012). O Ministério da Educação, por sua vez, define tradutor e intérprete como o profissional qualificado conhecedor, mediante formação específica, das duas estruturas linguísticas (Libras e Português) e das técnicas e estratégias de tradução. Além desses requisitos, é necessário ao intérprete educacional, especificamente, possuir um perfil compatível com a intermediação pedagógica (Quadros, 2004).

Em relação à acessibilidade linguística por meio dos intérpretes em todas as metodologias ativas de que trata este estudo, o Aluno 6 afirma:

Em todas atividades que tal metodologia fora aplicada, sempre havia intérpretes e não há como não participar. É bem integrativo e estimulante à participação.

A fala do estudante confirma a proposição de Morán (2015), que defende as metodologias ativas como propulsoras do envolvimento, participação significativa e interação entre todos os participantes. Além disso, ao afirmar que "não há como não 
participar", o respondente confirma o cumprimento, pelo intérprete, do seu papel de intermediador de línguas e culturas. Cabe ressaltar que apenas a presença do profissional não garante a acessibilidade, é necessário que todo o contexto de ensino e mediação das aulas e, nesse caso, das metodologias ativas sejam repensados por professores e estudantes, em parceria e colaboração, para que se adequem ao perfil bilíngue da turma, como afirma o aluno 7, corroborando, ainda, com Oliveira, Oliveira \& Fernandes (2020), que apontam para o movimento de não passividade do aprendiz: "Sim, acho que todo mundo estava envolvido e quando os interpretes não conseguiam atender logo os outros alunos se ajudavam". E complementado pelo Aluno 10: "sim, contribuem e facilitam o acesso a informações e conhecimentos, além de promover uma maior interação surdo/ouvinte"

Por outro lado, por se tratar de um contexto de formação de professores de Libras, portanto bilíngues, é necessário o estímulo à apropriação e à comunicação na língua pelos discentes do curso. Nesse sentido, o Aluno 16 destaca a importância do intérprete nos semestres iniciais, quando nem todos os ouvintes têm bom nível de fluência em Libras:

As metodologias foram acessiveis, mas no início do curso nem todos os ouvintes têm fluência na Libras, e isso causa uma separação clara entre ouvintes e surdos, tanto em discussões como na organização de trabalhos. Os interpretes tem um papel de grande relevância em sala aula.

Com isso, Megale (2009) discute sobre o bilinguismo e o biculturalismo como sendo duas realidades não necessariamente coexistentes, dito isso o TILS possibilita um apoio fundamental para a relação cultural nesse ambiente bilíngue. Visto que, segundo a autora, pelo fato de a língua ser "a principal ferramenta de internalização da cultura" (Megale, 2009, p. 93), os níveis de fluência, como já constatado pelo aluno 16, podem afetar o relacionamento entre alunos surdos e ouvintes.

Por fim, inserido em um cenário de respeito às particularidades e aos direitos linguísticos do Povo Surdo, alerta o Aluno 14 para a importância da disponibilização de materiais de apoio traduzidos para a Libras, reconhecendo a atribuição da Divisão de Tradução e Interpretação Libras/Português de "Traduzir textos acadêmicos e produtos informacionais em Libras/Língua Portuguesa para pessoas surdas da comunidade universitária” (Universidade Federal do Ceará, 2020):

Acho que o único cuidado que se deve ter, é o texto para estudo do aluno ter a opção de tradução em Libras, o que eu acho que a maioria tem, mas são acessíveis e até facilitam mais o estudo do aluno surdo.

Considerando o cenário em questão, a participação do profissional tradutor e intérprete durante a aplicação das metodologias ativas é essencial e não prejudica elementos centrais como o protagonismo e a autonomia dos estudantes, configurando-se como uma adaptação cultural e linguística das propostas.

Ressaltamos a demanda do estabelecimento de parceria professor/intérpretes de Libras na condução da mediação durante as aulas, que se reflete na cumplicidade e em leveza determinantes para que todos envolvidos se percebam parte desse processo de ensinagem, como vivenciado por Farias, Oliveira \& Cenci (2019) ao relatar experiência de tradução/interpretação no Ensino Superior, em que os profissionais TILS atuaram como mediadores linguísticos em sistema de parceria com educadores.

\section{Relação professor/aluno}

Apesar da utilização indistinta dos termos "professor", "educador", "ensino", "ensinagem", "aluno" e "estudante" nesta pesquisa, concebemos a perspectiva de Freire (2017b, p. 95-96), que afirma: “[...] não mais educador do educando, não mais

\footnotetext{
${ }^{2}$ Considerando que parte significativa dos ingressantes no curso não tem fluência na língua; e que, a partir do $5^{\circ}$ semestre, não há a presença dos TILS, a fala do aluno dialoga com a hipótese da interação para a aquisição de segunda língua (Paiva, 2014), que defende a interação entre nativos e não nativos (nesse caso surdos e ouvintes, respectivamente) como eixo fundamental da aprendizagem. Assim, as técnicas aplicadas possivelmente contribuem, também, para o aprendizado da Libras pelos alunos ouvintes em questão.
} 
educando do educador, mas educador-educando com educando-educador. Desta maneira, o educador já não é o que apenas educa, mas o que, enquanto educa, é educado, em diálogo com o educando que, ao ser educado, também educa"; e de Anatasiou (1998 apud Anastasiou \& Alves, 2015), que concebe a ensinagem no Ensino Superior, como processo do qual decorre a aprendizagem e exige uma relação de parceria e, portanto, horizontal entre educador e educando.

A horizontalidade na relação professor/aluno é vista pela maioria, mas há quem não tenha identificado, pois, nas respostas sobre aula expositivas, $41,2 \%$ não perceberam ou sentiram que essa relação foi bem estabelecida. $O$ fato de o professor estar em pé na frente da lousa explicando algum conteúdo pode provocar essa visualização hierárquica do docente, visão essa que pode rememorar modelos tradicionais, acionando o que Diesel, Baldez \& Martins (2017) dizem ser uma atitude passiva, onde receber e memorizar as informações são as únicas funções do aluno.

O uso de diversas metodologias pode se complementar, logo que nem todos os alunos são afetados por determinada estratégia e cabe ao professor ajudar o aluno a se aproximar dos seus objetivos e interesses. Ainda sobre uma perspectiva de mediação, Thadei (2018) retoma a discussão sobre ensino personalizado como uma forma de relembrar sobre as especificidades de cada indivíduo e sobre a necessária sensibilidade do educador diante desse fato.

Assim como na aula expositiva, no Painel integrado poucas pessoas acreditam que a relação de professor/aluno foi horizontal, isso nos leva a inferir que posturas minimamente tradicionais podem trazer à tona sentimentos dos modelos mais antigos, logo que durante o uso da metodologia há funções dentro da mediação que são pré-estabelecidas pelo professor, como o painelista, o apresentador etc., e de algum modo isso pode ser interpretado como a ausência de horizontalidade. No entanto é importante pensar que usar essas metodologias é mais do que ousar com coisas fora do comum ou mais do que estar em posição horizontal (conceitual e/ou estruturalmente), é necessário estar sempre repensando e remodelando essas práticas. Por isso Borges \& Alencar (2014) enfatizam as diversas possibilidades das metodologias ativas capazes de levar o aluno a uma experiência de autonomia e criticidade.

A relação do professor com o aluno e vice-versa é um ponto muito definidor para um bom aproveitamento das técnicas. Segundo Reeve (2009 apud Berbel, 2011), o professor deve adotar a perspectiva do aluno, deve acolher seus pensamentos, sentimentos e ações, sempre que manifestados, e apoiar o seu desenvolvimento motivacional e capacidade para autorregular-se. Esse processo de nivelamento entre os envolvidos nas metodologias faz com que os alunos possam se expressar mais livremente, sem que se sintam tão pressionados. Sobre isso, Freire (2017b) destaca a humildade como como requisito primeiro para a existência do diálogo, ressaltando que o educador deve ser aberto às diferentes pronúncias de mundo e à contribuição do outro.

Compreender a postura do professor de forma horizontal como parte da acessibilidade envolvida na sala de aula nos coloca numa dimensão bastante reflexiva. Ao serem questionados sobre se as MA foram suficientemente acessíveis, alguns relatos tocam na postura do professor participativo como parte dessa garantia. O Aluno 17 diz: "As metodologias ativas contribuem para que o acesso dos surdos seja maior por haver uma integração entre os alunos e pelo papel do professor ser um mediador da prática.", uma outra aluna também reflete sobre esse ponto dizendo: "Muito! Surdos e ouvintes em patamar de igualdade [...] e a participação plena e ativa de todos os envolvidos. Professora como mediadora e como participante do processo também." (Aluna 01). Percebe-se que o papel do professor mediador aproxima os alunos tanto no engajamento quanto na reflexão sobre a própria participação.

\section{Desenvolvimento de visão crítica}

As metodologias ativas apresentam-se como possível fonte do despertar da criticidade e autonomia dos indivíduos. Para Berbel (2011), esse processo acontece à medida em que o aprendiz se percebe como motivo primeiro da ação. Enquanto alternativas aos métodos tradicionais, elas são uma forma de colocar os educandos frente à sua realidade, valorizando as suas 
perspectivas e os seus saberes. Nesse sentido, Freire (2017a, p.32) instiga: "Por que não estabelecer uma 'intimidade' entre os saberes curriculares fundamentais aos alunos e a experiência social que eles têm como indivíduos?".

Questionados acerca da sua visão crítica sobre a realidade, a maioria dos respondentes afirmou que as metodologias ativas favoreceram esse desenvolvimento, conforme Tabela 1.

Tabela 1 - O uso da técnica contribuiu com o desenvolvimento da sua visão crítica sobre a realidade?

\begin{tabular}{|l|c|c|c|c|}
\hline \multicolumn{1}{|c|}{ Metodologia } & Participantes & SIM & NÃO & INDIFERENTE \\
\hline GV/GO & 24 & 21 & 0 & 3 \\
\hline Mapas Mentais & 22 & 14 & 1 & 7 \\
\hline Júri Simulado & 14 & 12 & 0 & 1 \\
\hline Painel Integrado & 12 & 8 & 1 & 3 \\
\hline Grupos de Integração Horizontal- & 9 & 8 & 0 & 1 \\
Vertical & & & & 1 \\
\hline Workshops e Projetos & 8 & 7 & 0 & 0 \\
\hline Exposição dialogada com leitura e & 17 & 17 & 0 & \\
\hline discussão de imagens & & & & \\
\hline
\end{tabular}

Fonte: Autores.

Proporcionalmente, as técnicas que propõem debates mais profundos, com reflexões individuais e coletivas - Exposição dialogada com leitura e discussão de imagens, Grupos de integração horizontal-vertical, Júri Simulado e GV/GO -, são aquelas em que os respondentes reconheceram maior potencial de desenvolvimento de sua criticidade. As metodologias ativas, portanto, se apresentam como potenciais desenvolvedoras do senso crítico e consequente ruptura com a anestesia histórica, que Freire (2005) define como a conformação com o status quo, a ausência da crítica sobre o estado das coisas. De maneira complementar, afirma o Aluno 11: "É muito bom poder expressar seu ponto de vista nas aulas, claro, respeitando sempre a opinião do outro"

A resposta do aluno remete ao "saber escutar" como elemento intrínseco à prática docente (Freire, 2017a); e às particularidades do diálogo em educação: "Não há, por outro lado, diálogo, se não há humildade. A pronúncia do mundo, com que os homens o recriam permanentemente, não pode ser um ato arrogante" (Freire, 2017b, p.111).

Desse modo, romper com os chamados métodos tradicionais, vai além da mudança conceitual do ensinar e do aprender, mas tem como consequência uma nova visão de mundo e, do ponto de vista do mercado, maior segurança e proatividade na futura atuação profissional a partir de um aprendizado contextualizado à realidade (Morán, 2015), como confirma o Aluno 14:

Gostei muito, de acordo com as minhas experiências o mais difícil para renovar as práticas de ensino é a falta de exemplo prático, muitas vezes ficamos apenas na teoria, parece um mundo idealizado que diverge da realidade. Por isso ter contato direto me ajudou na hora de planejar e colocar em prática o que aprendi.

\section{Formação profissional do professor de Libras}

O perfil do profissional a ser formado pelo curso de Letras Libras da UFC envolve, entre outras questões, a "percepção científico-ideológica, ter método de investigação e criatividade" (Universidade Federal do Ceará, 2012, p. 14). Sobre isso, Morán (2015) aponta que, se temos o objetivo de desenvolver estudantes criativos, precisamos oferecê-los oportunidades diversas para agir criativamente. Sobre a prática profissional, os achados apontam para um entendimento mais claro da relação entre teoria e prática após a aplicação das metodologias ativas, como pode-se observar na Tabela 2. 
Tabela 2 - O uso da técnica facilitou a compreensão da relação entre os conteúdos das disciplinas e a prática?

\begin{tabular}{|l|c|c|c|c|}
\hline \multicolumn{1}{|c|}{ Metodologia } & Participantes & SIM & NÃO & INDIFERENTE \\
\hline GV/GO & 24 & 24 & 0 & 0 \\
\hline Mapas Mentais & 22 & 16 & 1 & 5 \\
\hline Júri Simulado & 14 & 13 & 0 & 1 \\
\hline Painel Integrado & 12 & 11 & 0 & 0 \\
\hline Grupos de Integração Horizontal- & 9 & 9 & 0 & 1 \\
Vertical & & & & 0 \\
\hline Workshops e Projetos & 8 & 7 & 0 & 0 \\
\hline Exposição dialogada com leitura e & 17 & 17 & 0 & \\
\hline discussão de imagens & & & & \\
\hline
\end{tabular}

Fonte: Autores.

Seguindo o padrão observado no núcleo Visão crítica, percebe-se que, nas técnicas onde há maior interação e debate entre os pares, há, também, mais nítida relação entre teoria e prática. O GV/GO, que teve a participação de todos os respondentes, obteve unanimidade nas respostas, o que indica a sua eficácia nessa questão. De maneira complementar aos dados quantitativos, o Aluno 15 afirma:

O nível de aprendizagem, na minha opinião é mais alto, por que essa Metodologia busca incentivar os alunos a participar na sala de aula, também incentiva na forma criativa.

Por se tratar de um curso de formação de professores, se fez necessário investigar a contribuição das metodologias ativas no processo de aperfeiçoamento das práticas de ensino e avaliação. Sobre isso, o Aluno 1 comenta:

O uso das técnicas me ajudou a ter uma nova perspectiva sobre o 'ensinar' e o 'aprender' e sobre como ensinar e como aprender. Foram experiências que certamente vou reproduzir em minha futura atuação profissional.

A resposta do aluno corrobora com as respostas objetivas, conforme Tabela 3.

Tabela 3 - Sendo o curso de Letras Libras um curso de formação de professores, como você acha que a técnica contribuiu com a sua formação profissional?

\begin{tabular}{|l|c|c|c|c|}
\hline \multicolumn{1}{|c|}{ Metodologia } & Participantes & MUITO & MAIS OU MENOS & POUCO \\
\hline GV/GO & 24 & 17 & 5 & 2 \\
\hline Mapas Mentais & 22 & 17 & 3 & 1 \\
\hline Júri Simulado & 14 & 10 & 3 & 0 \\
\hline Painel Integrado & 12 & 7 & 1 & 1 \\
Grupos de Integração & 9 & 7 & & \\
Horizontal-Vertical & & & 1 & 1 \\
\hline Workshops e Projetos & 8 & 6 & 4 & 0 \\
\hline Exposição dialogada com leitura & 17 & 13 & & \\
e discussão de imagens & & & &
\end{tabular}

Fonte: Autores. 
Oliveira, Oliveira \& Fernandes (2020), ao defenderem as metodologias ativas, não excluem as aulas expositivas do processo educacional, sob o argumento de que a maioria dos profissionais do magistério atualmente em exercício é fruto de uma formação tradicional, que influencia diretamente a sua prática docente. Sobre o uso de metodologias ativas em substituição às aulas expositivas, relata o Aluno 9:

Eu acho fantástico, por que rompe com aulas tediosas e faz com que a gente repense nossas formas de aprender e de compartilhar os saberes.

Berbel (2011), por sua vez, aponta para a importância de que todos os participantes das metodologias acreditem no seu potencial pedagógico. Essa "transformação na educação" defendida também por Morán (2015), nasce da necessidade de que a escola acompanhe as transformações sociais. Para confirmar a proposição, o Aluno 4 afirma:

O uso das metodologias me fez enxergar que é possivel ensinar pra todos, pois, as metodologias usadas foram de fácil entendimento e diversificadas, contraponto as metodologias tradicionais. A minha aprendizagem foi absolutamente incrivel, consegui entender vários dos temas abordados em sala de aula e ainda trabalhar em grupo, eu farei sim algumas das metodologias ativas na minha sala de aula e ainda complementar meus trabalhos acadêmicos com as metodologias aprendidas.

Em outras palavras, a ruptura com o tradicionalismo em educação é uma mudança prática e, sobretudo, conceptual.

Confirmando o exposto, o Aluno 18 relata experiência em que aplicou uma metodologia ativa em seu estágio de regência, componente curricular obrigatório nos cursos de formação de professores (Universidade Federal do Ceará, 2012):

"Já utilizei algumas dessas metodologias em prática de sala de aula de estágio. Senti uma maior motivação dos alunos em participar e uma interação forte entre surdos e ouvintes."

A fala do Aluno 18 confirma as contribuições das metodologias ativas no que se refere à interação entre os participantes e, ainda, a sua aplicabilidade em contextos específicos de interação bilíngue entre surdos e ouvintes, mediante adaptações culturais e linguísticas. Por fim, vai ao encontro das proposições teóricas que citam a urgência das mudanças profundas na educação (Berbel, 2011; Morán, 2015) ao se posicionar como um professor que, em seu processo de formação, experienciou e, por identificação, aplicou metodologias ativas.

\section{Conclusão}

Este estudo, apesar de seu caráter transversal, buscou contribuir com o crescimento das investigações sobre Metodologias Ativas no campo das Ciências Humanas. Os resultados observados apontam para a efetividade de todas as sete MA de que trata o estudo, sobretudo aquelas em que há maior nível de interação com os pares e práticas mais dinâmicas. A maioria dos respondentes avaliou positivamente todas as estratégias, destacando a relevância delas principalmente no que se refere ao processo de formação docente, desenvolvimento da criticidade e da autonomia discente. Por outro lado, as respostas que as consideram como estratégias não eficazes devem ser examinadas e levadas em consideração para o planejamento global de mediação da educação bilíngue e bicultural no curso de Letras Libras, afinal as especificidades individuais e de cada turma interferem diretamente na condução dessas práticas. 
Compreendendo que este estudo revelou uma boa relação da maioria dos alunos com as Metodologias Ativas, entendese que estas podem servir como pontes para uma melhor interação cultural e apreensão de conhecimentos promovidos pelo curso de Letras Libras. O que se apresentou como dados de "insucesso" servirão como base para adaptações futuras nas próprias metodologias.

Estar disposto a mudar estruturas e formas de construção do mundo é também se dispor a refletir sobre as próprias motivações e, principalmente, sobre a relação (in)direta entre tentar e conseguir. Com isso, é necessária uma postura humilde e, ao mesmo tempo, ousada sempre buscando novas formas de acessar conhecimento, buscando inclusive dentro do seu espaço de vivência profissional.

Sugere-se, por fim, o desenvolvimento de novas pesquisas que investiguem as percepções do mesmo público acerca da utilização de metodologias ativas na avaliação da aprendizagem, além de estudos voltados ao bilinguismo e, sobretudo, ao biculturalismo, sabendo que as experiências aqui apresentadas identificam, mesmo não sendo o objeto do estudo, elementos limitantes e/ou potencializadores no uso das Metodologias Ativas em ambiente bilíngues e biculturais do ensino superior. Indica-se, ainda, pesquisas a fim de compreender como as Metodologias Ativas se dão no ambiente virtual, predominante no período pandêmico, tendo em vista que isso abre espaço para dados comparativos, além da possibilidade de se entender como acontece o uso, as adaptações necessárias e o nível de adesão dessas metodologias nesse novo contexto.

\section{Referências}

Anastasiou, L. G. C. \& Alves, L. P. (2015). Processos de ensinagem na universidade. (10a. ed.) Joinvile: Univille.

Baalbaki, A. C. F. (2017) Línguas, escola e sujeito surdo: análise do "Relatório sobre a política linguística de educação bilíngue - Língua Brasileira de sinais e Língua Portuguesa". Cadernos de Letras da UFF. Dossiê: Línguas e culturas em contato, (53), 323-342.

Bardin, L. (2016). Análise de conteúdo. São Paulo: 70.

Beck, C. (2018) Metodologias ativas: conceito e aplicação. Andragogia Brasil. https://andragogiabrasil.com.br/metodologias-ativas/.

Berbel, N. A. N. (2011). As metodologias ativas e a promoção da autonomia de estudantes. Semina, 32(1), 25-40. https://www.uel.br/revistas/uel/index.php/seminasoc/article/view/10326

Bordenave, J. D. \& Pereira, A. M. (2014). Estratégias de ensino-aprendizagem. (33a ed.). Petrópolis, RJ: Vozes.

Borges, T. S. \& Alencar, G. (2014) Metodologias ativas na promoção da formação crítica do estudante: o uso das metodologias ativas como recurso didático na formação crítica do estudante do ensino superior. Cairu em Revista, 3(4), 119-143.

Bortoni-Ricardo, S. M. \& Dettoni, R. V. (2009) Diversidades linguísticas e desigualdades sociais: aplicando a pedagogia culturalmente sensível. Cenas de sala de aula. (pp. 81-104). Campinas: Mercado de Letras.

Brasil. (2016). Resolução N510, de 07 de abril de 2016. Brasília. http://conselho.saude.gov.br/resolucoes/2016/Reso510.pdf

Campello, A. R. (2008) Aspectos da visualidade na educação de surdos. Tese de doutorado, Universidade Federal de Santa Catarina, Florianópolis, SC, Brasil.

Campos, M. L. I. (2018) Educação Inclusiva para Surdos e as políticas vigentes. Tenho um aluno surdo, e agora? Introdução à Libras e à Educação de Surdos (pp.37-61). São Carlos: EdUFSCar.

Dantas, L. J. (2018) Curso de tecnologia e perfil acadêmico de docentes: um estudo em instituição pública estadual de educação profissional tecnológica. Dissertação de Mestrado, Centro Estadual de Educação Tecnológica Paula Souza, São Paulo, SP, Brasil.

Diesel, A., Baldez, A. L. S. \& Martins, S. N. (2017). Os princípios das metodologias ativas de ensino: uma abordagem teórica. Revista Thema. 14(1), 168288. http://periodicos.ifsul.edu.br/index.php/thema/article/view/404

Farias, M. D., Oliveira, F. K. \& Cenci, A. (2019) Atuação do tradutor intérprete de Libras no ensino superior: implicações na disciplina de educação inclusiva. Revista Research, Society and Development, 9(1). https://rsdjournal.org/index.php/rsd/article/view/1843/1568 .

Freire, M. (2014) Educador. (4a ed.) São Paulo: Paz e Terra.

Freire, P. (2002) Educação: o sonho possível. O educador: vida e morte. (12a ed.) Rio de Janeiro: Graal. pp.89-101.

Freire, P. (2005) Pedagogia da esperança: um reencontro com a pedagogia do oprimido. (12a ed.) Rio de Janeiro: Paz e Terra. 
Freire, P. (2017a) Pedagogia da autonomia: saberes necessários à prática educativa. (55a ed.) São Paulo: Paz e Terra.

Freire, P. (2017b) Pedagogia do oprimido. (64a ed.) Rio de Janeiro: Paz e Terra.

Gesser, A. (2012) O ouvinte e a surdez: sobre ensinar e aprender a Libras. São Paulo: Parábola.

Gil, A. C. (2019). Métodos e técnicas de pesquisa social. (7a ed.). São Paulo: Atlas.

Gonçalves, A. M. (2020) A prática docente e a utilização de metodologias ativas na educação técnica profissional. Dissertação de Mestrado, Centro Estadual de Educação Tecnológica Paula Souza, São Paulo, SP, Brasil.

Lakatos, E. M. \& Marconi, M. A. (2017). Fundamentos de metodologia científica. (8a ed.). São Paulo: Atlas.

Laraia, R. B. (2001) Cultura: um conceito antropológico. (14a ed.) Rio de Janeiro: Zahar.

Marques, C. J. F., Araujo, L. A. S., Loureiro, M. C. B \& Munguba, M. C. (2020) A Educação Bilíngue na Universidade Federal do Ceará: o perfil do alunado do curso de Letras Libras. Revista Research, Society and Development, 9(7). https://rsdjournal.org/index.php/rsd/article/view/3891

Mattar, J. (2017) Metodologias ativas: para a educação presencial, blended e a distância. São Paulo: Artesanato Educacional.

Megale, A. H. (2009) Duas línguas, duas culturas? A construção da identidade cultural de indivíduos bilíngues. Veredas - Revista de Estudos Linguísticos. https://www.ufjf.br/revistaveredas/files/2009/12/artigo062.pdf .

Mertizig, P. L. L., Burci, T. V. L., Silvia, D. H. I. O \& Basso, E. O. (2020) Reflexões sobre práticas coletivas e metodologias ativas no ensino superior. Revista Aproximação, 2(2), 45-59. https://revistas.unicentro.br/index.php/aproximacao/article/view/6322

Minayo, M. C. S, Deslandes, S. F. \& Gomes, R. (2015). Pesquisa social: teoria, método e criatividade. (34a ed.). Rio de Janeiro: Vozes.

Moran, J. (2015) Mudando a educação com metodologias ativas. Convergências midiáticas, educação e cidadania: aproximações jovens. Coleção Mídias Contemporâneas. Ponta Grossa: PROEX/UEPG.

Oliveira, F. R., Oliveira, D. H. I. \& Fernandes, A. H. (2020) Metodologias ativas: repensando a prática docente no contexto educacional do século XXI. Revista Aproximação, 2(2). https://revistas.unicentro.br/index.php/aproximacao/article/view/6360

Paiva, V. L. M. O. (2014) Aquisição de Segunda Língua. São Paulo: Parábola.

Paiva, M. R. F., Parente, J. R. F., Brandão, I. R. \& Queiroz, A. H. B. (2015) Metodologias ativas de ensino-aprendizagem: revisão integrativa. Sanare, 15(2), $145-153$.

Pereira, M. C. C. (2011) Aquisição da língua portuguesa escrita por crianças surdas. Anais do SIELP. Uberlândia: EDUFU. http://www.ileel.ufu.br/anaisdosielp/wp-content/uploads/2014/06/volume_1_artigo_066.pdf

Quadros, R. M. (2004) O tradutor e intérprete de língua brasileira de sinais e língua portuguesa. Secretaria de Educação Especial; Programa Nacional de Apoio à Educação de Surdos. Brasília: MEC; SEESP.

Severino, A. J. (2016) Metodologia do trabalho científico. São Paulo: Cortez.

Silva, T. T. (2017) Documentos de identidade: uma introdução às teorias do currículo. (3a ed.) Belo Horizonte: Autêntica.

Souza, J. C. (2015) Fundamentos da metodologia de ensino ativa (1890-1931). Anais... Reunião Nacional da ANPED. Florianópolis: UFSC. http://www.anped.org.br/sites/default/files/trabalho-gt02-4216.pdf .

Thadei, J. (2018) Mediação e educação na atualidade: um diálogo com formadores de professores. Metodologias ativas para uma educação inovadora: uma abordagem teórico-prática. Porto Alegre: Penso.

Universidade Federal do Ceará. (2012) Projeto pedagógico curricular do curso de licenciatura em letras: língua brasileira de sinais (libras). https://si3.ufc.br/sigaa/verProducao?idProducao=497717\&key=cf0671f834a8a9085e1406a4b 1a76362

Universidade Federal do Ceará. (2020) Divisão de tradução e interpretação libras/português. https://acessibilidade.ufc.br/pt/estrutura/divisao-de-traducao-eeinterpretacao-librasportugues/. 